\title{
O impacto da economia de educação global nos processos de ensino e de aprendizagem: uma análise das políticas públicas e perspectivas das práticas educacionais
}

\author{
Verônica Gesser, Universidade do Vale do Itajaí, Brasil \\ Valéria Silva Ferreira, Universidade do Vale do Itajaí, Brasil
}

\begin{abstract}
Resumo: Este trabalho tem como objetivo caracterizar as atuais politicas públicas e perspectivas de práticas educacionais, cujos princípios fundamentam-se na lógica da economia de educação global, visando refletir sobre possíveis impactos nos processos de ensino e de aprendizagem no âmbito dos contextos educacionais locais. Esse modelo reflete a influência da lógica política e econômica neoliberal, o qual caracteriza um contexto governado pelas leis de mercado e pela descaracterização do Estado de Bem-estar Social democrático; ou seja, a redução do Estado e a valorização do "mercado e quase-mercado". Exemplo disso é o que está acontecendo no Brasil com a expansão dos serviços e dos produtos educacionais terceirizados. Essa idéia vem sendo aplicada pela descentralização da responsabilidade da Educação Básica para os municípios brasileiros. Dessa forma, o orçamento para os serviços, os produtos e a formação continuada está sendo transferido para empresas nacionais e multinacionais especializadas, muitas vezes sob o rótulo de entidades sem fins lucrativos (novas filantropias; empresas associadas; ou seja, a terceira via). Assim sendo, a educação brasileira vem sofrendo o impacto da desnacionalização do Estado, o que está provocando profundas mudanças em como as politicas públicas educacionais vêm sendo praticadas no âmbito de cada município brasileiro. Consequentemente, a educação brasileira está sendo concebida como um comodity.
\end{abstract}

Palavras-Chave: economia de educação global, políticas públicas, impactos na prática pedagógica

\begin{abstract}
This paper aims to characterize current public policies and educational practice perspectives, which principles are based on the logic of global education economy, aiming to reflect on possible impacts on processes of teaching and learning within the local educational contexts. This model reflects the neoliberal political influence and economic logic, which features a context governed by the laws of the market and the democratic Social Welfare State mischaracterization; that is, state reduction and "market and quasi-market" enhancement. Example of this is what is happening in Brazil with the expansion of educational services and outsourced products. This idea has been applied by Basic Education responsibility decentralization for the municipalities. Thus, the budget for the services, products and continuing education is being transferred to specialized national and multinational enterprises, often under the label of nonprofits entities (new philanthropies, associated companies, that is, the third sector). Therefore, the Brazilian education has been suffering state denationalization impact, which is causing profound changes in how educational public policies are being practiced within each Brazilian municipality. Consequently, Brazilian education is being conceived as commodity.
\end{abstract}

Keywords: Economy of Global Education, Public Policies, Impacts on Teaching Practice

\section{Introdução}

educação e o mundo contemporâneo sofrem transformações estruturais significativas com o $\triangle$ advento das novas tecnologias por meio dos avanços da Ciência. O processo histórico do 1 desenvolvimento da ciência e da tecnologia universalizou os meios de vida do homem moderno, proporcionando situações objetivas para que ele seja, simultaneamente, universal e local. Essas transformações vivenciadas pela humanidade, neste novo milênio, estão diretamente ligadas ao desenvolvimento das novas tecnologias da comunicação e da informação que, atualmente, ganham ênfase a partir do movimento de aproximação entre as diversas indústrias do setor tecnológico e das novas mídias.

Essa situação potencializa as condições de comunicação entre as pessoas e as organizações empresariais ou educativas nos mais diversos setores do contexto global e local. No entanto, como em toda era de transição, coexistem, ainda, nesse mesmo período de tempo e espaço, valores antigos

Revista Internacional de Ciencias Sociales

Volume 4, Número 1, <http://lascienciassociales.com>, ISSN 2530-4909

(C) Global Knowledge Academics.Verônica Gesser, Valéria Silva Ferreira.

Todos los derechos reservados. Permisos: soporte@gkacademics.com

Republicado de Revista Internacional de Ciencias Sociales Interdisciplinares 4(1), 2015 (pp. 1-9) 
(ligados aos velhos paradigmas da sociedade) com os valores deste mundo em transformação; ou seja, valores conectados ao paradigma da sociedade emergente. Tais transformações estão relacionadas à emergência de uma sociedade global e digital não percebida anteriormente. Esse contexto vem sendo marcado, principalmente, por políticas econômicas mundiais, normalmente planejadas e coordenadas por países centrais no âmbito do mercado e, por consequência, por organismos multilaterais e internacionais, como o Banco Mundial (BM), o Fundo Monetário Internacional (FMI), entre outros. Tem-se como pano de fundo uma lógica neoliberal sustentada pela ausência do Estado, impulsionada pela política de globalização da economia mundial. Essa é a lógica que vem direcionando os rumos das políticas educacionais e sociais da América Latina. Conforme Borón:

A hegemonia ideológica do neoliberalismo e sua expressão política, o neoconservadorismo, adquiriram uma desabitual intensidade na América Latina. Um de seus resultados foi o radical enfraquecimento do Estado, cada vez mais submetidos aos interesses das classes dominantes e renunciando a graus importantes de soberania nacional diante da superpotência imperial, a burguesia transnacionalizada e suas 'instituições' guardiãs: O FMI, o Banco Mundial e o regime econômico que gira em torno da supremacia do dólar. (Borón, 2003: 78).

Embora cada um dos países da América Latina tenha vivido momentos distintos, alguns anteriores a esse contexto, foi a partir da década de 1990 que essa lógica neoliberal, dirigida pela esfera econômica e sob a égide do mercado, vem determinando os contextos internos de cada país alicerçados na ideia de que: "Qualidade seria sinônimo de privado, enquanto que ineficiência e corrupção seriam intrínsecas ao que é público" (Santos, 2008: 81).

No Brasil, exemplos claros dessa visão ideológica foram as privatizações realizadas no âmbito do governo de Fernando Henrique Cardoso; a redução, também nesse período, de investimentos nas instituições de ensino superior pública brasileira; a expansão do ensino superior e o acesso do investimento público da educação básica pela esfera privada. Santos (2008: 81) explica: "É a partir desta ideologia que se vem diminuindo a capacidade do Estado de formular e executar políticas públicas".

Nessa linha de compreensão é que vamos delinear, no contexto da América Latina, como as políticas públicas, nacionais e internacionais dão materialidade a mudanças na política educacional do país, pois estas conferem a direção dos eixos políticos de seu projeto, os quais foram delineados a partir dos movimentos e/ou fóruns internacionais promovidos nos anos de 1990.

Estar atualizado no conhecimento de políticas públicas é uma exigência que se impõe a todos os profissionais que atuam no campo educacional, sobretudo porque, nas duas últimas décadas, procedeu-se à revisão da finalidade da educação no país e no mundo. As mudanças operadas pela via da promulgação de leis e aprovação de programas e planos internacionais interferiram de modo significativo no direcionamento da vontade política presente na esfera local, impulsionando, inclusive, um amplo movimento de reformas na própria sociedade. Esses movimentos/fóruns de proposições e projetos para a reforma educacional tomou maior força a partir da conferência de Jomtiem/Tailândia, em 1990. No Brasil, entretanto, foi a partir da Lei de Diretrizes e Bases (LDB) de 1996 que as principais mudanças começaram a ter visibilidade no âmbito dos contextos educacionais. Dessa forma, as políticas públicas constituem-se como veículo das proposições governamentais, legitimando as opções políticas e o aporte ideológico a elas alinhavado. É a partir desse cenário que pretendemos caracterizar as políticas públicas educacionais na América Latina, seus impactos e, em especial, exemplificar situações do contexto brasileiro.

\section{Caracterização e impactos das políticas públicas educacionais na América Latina}

As políticas públicas educacionais no cenário da América Latina seguem o panorama delineado pelo contexto das políticas internacionais as quais estão centradas e dirigidas pela lógica econômica e de mercado dos países centrais do globo. Essa situação faz-se notar pela consolidação de uma história 
de dependência internacional que vem sendo assegurada por pactos econômicos acordados entre as instituições financeiras e cada um dos países. Dessa maneira, acabam por determinar, de uma forma ou de outra, as macro políticas governamentais nos diferentes setores da nação. Assim, o "atrelamento das práticas governamentais ao interesse do capital financeiro mundial se expressa também na esfera educativa" (Santos, 2008: 82).

Segundo Sposati (2011: 107), na América Latina, a autonomia dos Estados ou Nações fica sobre a custodia das agências de financiamento internacionais (FMI, BID). Como consequência, essa dependência reduz o crescimento interno das nações com suas responsabilidades públicas, ficando estas submissas à presença de uma política neoliberal, ou seja, de Estado mínimo. Nessa esfera do globo: "Ocorreu a recentralização do social no mercado tornando-o lócus privilegiado de ofertas sociais o que ampliou a privatização da educação, saúde, previdência social, assistência social [...]. O enquadramento neoliberal imposto pelo FMI aos países latino-americanos subordinou a ampliação da agenda pública ao mercado e à filantropia e configurou a oposição entre o Estado e os reclamos dos movimentos sociais" (Sposati, 2011: 107).

Vale ressaltar que, embora haja esforços concentrados no âmbito do contexto latino-americano, como, por exemplo, o Mercado Comum do Sul (MERCOSUL) e governos com plataformas democráticas, não há, ainda, uma visão unificada e suficientemente articulada em prol de suas próprias políticas, em especial na área da educação. A subordinação histórica aos centros econômicos mundiais sofridos pelos países latino-americanos ainda vem marcando e determinando as bases internas desses países. Para Sposati (2011: 107): "Não se dispõe na América Latina de lócus de defesa de direitos sociais mesmo com a emergência de governos com agendas centradas em interesses democráticos e populares”. A nosso ver, as políticas públicas da educação são exemplos evidentes desse contexto em análise.

No Brasil, estamos vivendo, desde a década de 1990, impactos dessa agenda de políticas internacionais resultantes da globalização da economia pelas políticas de avaliação e de currículo no âmbito de todas as modalidades educativas. Para além das privatizações de empresas estatais nesse período, políticas de avaliação em larga escala, como o SAEB, foram implementadas e ainda estão sendo. No entanto, não houve significativos indícios de aumento de qualidade na educação básica. Por exemplo, segundo Alves (2007: 528): “A divulgação dos resultados pouco promissores do SAEB 1999 e 2001 trouxe desconforto para o Governo Federal e preocupação para todos que se interessam pelo acompanhamento da evolução de indicadores educacionais". Exemplos semelhantes também são observados em outros países da América Latina, porém o Brasil é considerado liderança nesse contexto.

Esse desconforto refletiu ainda mais nos municípios brasileiros e foi alvo de críticas e plataformas eleitorais para reverter esse quadro. Dessa forma, os currículos, a formação de professores e, sobretudo, o trabalho docente foram questionados fortemente. Esse cenário constituído proporcionou uma análise ligeira e oportunista sobre a eficiência dos serviços públicos. Tudo isso, mais o advento da municipalização do ensino fundamental e as possibilidades do FUNDEB, possibilitaram o avanço do mercado das empresas de negócios educacionais sobre o orçamento público da educação básica.

No Brasil, as empresas denominadas de "sistemas de ensino", são empresas que produzem e vendem materiais didáticos, promovem cursos para os professores em um sistema de franquia. Esses sistemas incluem a compra de um "pacote" pedagógico, ao qual incluem apostilas, livro de orientação ao professor, formação continuada, avaliação etc. O assédio sedutor das empresas educativas e a promessa de melhorar os índices das avaliações do MEC tem sido a escolha mais fácil e rápida de alguns governos municipais brasileiros. A adoção desses sistemas concentra o investimento das verbas municipais em "kits" pedagógicos. Concordamos com a hipótese de Adrião et al.: "Parece-nos que tais empresas, mais do que meras fornecedoras de materiais e equipamentos, passam a incidir sobre o desenho da política educacional local e sobre a organização do trabalho docente e administrativo desenvolvido em cada uma das unidades de ensino da rede pública, razão pela qual se tornam parceiras dos governos municipais" (Adrião et al., 2009: 4).

A parceria entre o público e o privado é característica do Estado moderno, diferenciando-se nos anos 70 e consolidando-se nos anos 80 e expandindo-se para todo o mundo a partir da década de 90 
(Santos, 2007). No Brasil não foi diferente. Diante da ideia de que a administração pública é ineficiente na esfera gerencial (Bresser Pereira; Spink, 1988), Boaventura de Souza Santos explica em seu relatório de pesquisa de 2007 (Santos, 2007: 1): "O Estado passara de solução a problema na esfera pública, era associada a monopólios, ineficiência, burocracia, impossibilidade de escolha e a um sem número de outros males". Nessa perspectiva, a educação municipal busca convênios com instituições privadas, tanto para formação de seus professores como também para compra de materiais didáticos. Em síntese: "As parcerias público-privadas são uma forma de organização híbrida, que testa as fronteiras de categorias estabelecidas na economia, no direito, na política, etc. O termo parceria público-privada subsume um espectro amplo de contratos entre o Estado e agentes privados, remetendo para uma divisão de trabalho entre público e privado, em que este assume a realização de tarefas públicas" (Santos, 2007: 9).

Apesar desses impactos, o que pode considerar-se no caso brasileiro é o fato de que a partir das duas últimas décadas houve sim um crescimento no número de matrículas do Ensino Fundamental. No entanto, isso não significa que esse índice por si só seja indício de aumento na qualidade e nas condições de ensino das escolas brasileiras. Para Libâneo (2006), a análise dos impactos das políticas públicas educacionais em termos de qualidade na educação não se resume aos índices alcançados em avaliações de caráter genérico em torno de análises estatísticas nacionais. $\mathrm{O}$ autor argumenta que a qualidade de uma política educacional e/ou da qualidade de ensino nas escolas necessita de instrumentos de regulação que possam "pensar a escola 'por dentro', analisando os elementos que a constituem, os processos de aprendizagem e de ensino e seus resultados" (Libâneo, 2006: 71). O autor explica:

A dissociação entre os dois tipos de análise induz a percepções viesadas, em que as visões globalizantes (análise externa) podem tender a não captar as peculiaridades internas da escola, e as visões da escola e da sala de aula (análise interna) tendem a desconhecer ou a desconsiderar os determinantes sociais e culturais. As análises críticas das políticas educacionais e do sistema de ensino perdem a força analítica se não tiverem como referência a escola e suas funções sociais e pedagógicas. Do mesmo modo, os profissionais envolvidos no campo interno da escola podem ter reduzida a eficácia pedagógica e social do seu trabalho, se não tiverem uma visão integrada e crítica dos determinantes sociais e culturais do sistema de ensino. (Libâneo, 2006: 71)

Diante dessa explicação e argumentação, como constituir políticas públicas educacionais e práticas educativas de qualidade no âmbito da América Latina se os princípios determinantes de sua lógica norteadora internas são sempre advindos de políticas externas e de contextos distintos? Ainda, recorrendo ao mesmo autor, podemos constatar que: "As políticas educacionais pressupõem políticas para a escola, e estas devem basear-se em necessidades e em demandas originadas nos contextos concretos de ensino e na aprendizagem das escolas e das salas de aula" (Libâneo, 2006: 83). Ao contrário disso, o que se vive historicamente no contexto latino-americano, inclusive nas últimas duas décadas, é um histórico subalternizante influenciado fortemente pelas determinações de políticas econômicas internacionais assentadas na lógica neoliberal de mercado.

De outra maneira, pode-se afirmar que, por muitos anos, a América Latina vem sofrendo desvios de funções de suas políticas e um desempoderamento estatal, dado o controle externo e o poder de alguns países centrais na esfera política e financeira do globo. Convergentemente, Sposati (2011: 108) explica que essa condição de subordinação vem sendo "[...] assentada desde a colonização dos países latino-americanos e não superada nos movimentos de independência, ou na sua conformação da república". Como consequência, temos agora uma nova acrobacia neoliberal. "Trata-se agora, de identificar os mais precarizados e criar formas de sua 'melhoria social' ou redução de sua indigência e não de estender a todos as condições dignas de respostas às necessidades sociais como marca de reconhecimento da cidadania. O enfrentamento [...], cuja presença é de ordem fortemente econômica, passou a ser tratado no âmbito da ordem social [especialmente educação, saúde, etc.]" (Sposati, 2011: 108).

Novamente, o que se constata é o fato de que são as políticas públicas educacionais internas que conferem qualidade ou não as aprendizagens internas às escolas e às salas de aula. Nesse sentido, 
são as políticas e as diretrizes governamentais de um país as responsáveis pela elevação dos índices de qualidade em todos os setores: sociais, educacionais, culturais, entre outros. Isso não significa negar que as políticas externas não possam contribuir ou que não possam fazer parte deste jogo pela busca de qualidade educacional e de vida. No entanto, há de considerar-se, em primeira instância, o que se faz necessário a partir das condições e das prioridades internas de modo a serem compatíveis ou comparáveis às externas.

Assim sendo, destacamos que se confere indispensável observar, conforme Libâneo (2006), a ponta do sistema, ou seja, a sala de aula. O autor argumenta: "É na ponta do sistema de ensino, nas escolas, que se constrói e se avalia a qualidade da escolarização" (Libâneo, 2006: 82). No caso brasileiro, observar que houve um aumento de matrículas a partir das duas últimas décadas não significa que as aprendizagens das crianças elevaram-se ou que seus padrões sociais também foram, por essas razões, alterados. Conforme Luz e Gesser (2007), o aumento de matrículas, nesse período, esteve muito mais ligado à política de financiamento do Ensino Fundamental, por meio do FUNDEF, do que propriamente pelos matriculados, pois o valor destinado às escolas era (e ainda é, no caso do FUNDEB) pelo número de matrículas.

Entretanto, as fragilidades das políticas educacionais dos países da América Latina não podem ser vistas como única e exclusivamente resultantes das determinações de políticas internacionais ou de políticas externas à nação. Obviamente que também é patente para seus cidadãos, inclusive no Brasil, um histórico de corrupção e de autoritarismo governamental vivido no contexto dos países latino-americanos. Esse fator, por consequência, afeta de forma significativa as prioridades determinadas para cada nação, especialmente as políticas de caráter social: educação, saúde, previdência, entre outras. Assim sendo, aqui a presença internacional pode ter e poderia ter ainda mais impacto no que se refere à distribuição de renda e às condições socioeconômicas para que os índices de escolaridade atingissem melhores patamares. O PISA, por exemplo, demonstra uma grande distância entre os países mais desenvolvidos do mundo e os países latino-americanos, entre eles, o Brasil, com baixo indicador quando comparado aos demais que participam. Nessa perspectiva, as políticas externas são importantes partes do jogo pela qualidade educacional.

A análise externa das questões escolares é necessária. Ela alerta para uma visão política e contextualizada das coisas. Entretanto, em todas as modalidades de educação, os processos são de caráter endógeno: eles acontecem de dentro para fora. $\mathrm{O}$ que confere qualidade ou não ao sistema de ensino são as práticas escolares, as práticas de ensino. É preciso, pois, considerar que os critérios democráticos de eficácia das políticas e diretrizes educacionais devem incidir sobre a efetividade das ações pedagógicas, isto é, a qualidade interna das aprendizagens escolares. (Libâneo, 2006: 83)

Partindo dessas compreensões e interlocuções, o grande desafio aos países da América Latina neste século 21 está relacionado à superação dessa condição e às heranças do século XX que vêm sendo sustentadas sob a lógica do neoliberalismo. Para Sposati (2011: 105), há de se confrontar todas as formas de desigualdades, especialmente as de ordem econômicas e sociais para buscar alguma garantia de universalidade e igualdade de direitos. Não obstante, há de se criar condições de tornar estas acessíveis aos diversos estratos da população e, principalmente, aos que habitam em uma situação de precariedade e com pouca ou nenhuma condição de dignidade, trabalho e cidadania. Enfatiza a autora: "No século 21, colocam-se novos campos de confronto para o enfrentamento das desigualdades sociais, econômicas, jurídicas, culturais, políticas e a constituição da universalidade de acesso que respeite as diferenças e, com ela, a construção do direito à equidade" (Sposati, 2011: 105).

Nessa linha de análise, diante dos desafios já postos e apesar dos esforços externos e internos já empregados nessas duas últimas décadas em relação à garantia de Educação para todos, segundo a Unesco (1990: 22), o panorama mundial de educação ainda é preocupante, não apenas na América Latina. No entanto, o quadro de condições e de índices do contexto latino-americano ainda é mais frágil. Em pleno século 21, segundo Damásio (2008: 8), vive-se um contexto de fracasso dos sistemas educacionais. Esse panorama “[...] expressa a centralidade desses organismos internacionais na influência sobre as políticas governamentais para a educação mundial", e com mais severidade nos países periféricos do globo, entre eles, os da América Latina. 
Para Trojan (2009), depois de duas décadas da conferência mundial na Tailândia, no que se refere aos países latino-americanos, ainda se faz imperiosa, especialmente para melhor avaliação dos compromissos lá assumidos, uma avaliação contínua e particularizada sobre os efeitos das propostas em relação às políticas educacionais. Essa condição parece necessária principalmente pelo fato de essas políticas, como já vimos observando ao longo deste trabalho, serem financiadas por organismos multilaterais internacionais, o que gera maior dependência em todos os níveis de desenvolvimento de cada nação. Trojan (2009: 1) ainda explica: "Essa dependência das organizações internacionais está associada ao processo de globalização, que efetivou ajustes no modelo capitalista de produção, distribuição e consumo". Essas reformas ou ajustes, afirma Souza (2002), são expressivas de origem econômica e política em todas as nações, especialmente tomando como foco a reforma do Estado, e educação não ficou isenta dessa reforma. Trojan explica:

\begin{abstract}
$\mathrm{Na}$ educação, a reforma do estado e a redução dos gastos públicos causaram impactos na gestão do sistema na maioria dos países latino-americanos, destacando-se a municipalização [no Brasil inclusive] da educação obrigatória, mudanças no modelo de gestão [descentralização e gestão participativa] e a instituição de sistemas nacionais de avaliação [no Brasil também]. [...] as reformas educacionais realizadas na América Latina destaca três objetivos da política no nível regional: o reposicionamento da educação no quadro das estratégias de desenvolvimento como uma política prioritária, cujo instrumento principal foi o financiamento; a geração de nova etapa de desenvolvimento educacional impulsionada por uma nova gestão apoiada na reestruturação do papel do Estado; e a melhoria da qualidade e da equidade na educação. (Trojan, 2009: 1-2)
\end{abstract}

Na reestruturação do papel do Estado, ressalta-se a possibilidade, a partir da LDB, da parceria do estado e da iniciativa privada. Como já dito anteriormente, o mercado que explora a educação (Cury, 2001) valeu-se nos argumentos das avaliações de larga escala para comercializar os seus produtos comerciais, sobretudo os chamados sistemas apostilados.

Arelalo (2008) e Adrião et al. (2009) investigam esse fenômeno na rede pública de São Paulo, o qual apresenta, desde 1996, uma significativa expansão das responsabilidades do setor público para o privado. “[...] subvencionando-a, em troca da transferência da lógica de organização privada para o setor público, ao invés de reverter esses recursos públicos para a melhoria e/ou consolidação do aparato" (Adrião et al., 2009: 803-804).

Concordamos com Dourado (2007: 922) que a referida expansão articula-se a processos mais amplos como o educativo e a "dinâmica com que se constrói o projeto político-pedagógico e se materializam os processos de organização e gestão da educação básica" (Dourado 2007: 922), o que torna o problema mais grave, em nossa opinião. Assim sendo, essa expansão destitui o papel do educador como um especialista na educação, que deveria ser capaz de planejar os processos de ensino, de aprendizagem e de avaliação. Cabe aos professores seguirem apostilas com textos e exercícios massificadores e treinos mecânicos como formação continuada.

O dinheiro público da educação é desviado para esses kits que tem a pretensão de elevar os níveis percentuais das avaliações de grandes escalas para o atendimento dos acordos internacionais, que realmente estão contribuindo para uma falsa identidade do professor, piorando as condições de trabalho docente e, por fim, trazendo uma aprendizagem enciclopédica e destituída de criticidade.

No Brasil, essas são as principais condições e situações que se vive no contexto da educação. Conforme já mencionamos anteriormente, apesar do FUNDEF (Brasil, 1997) e do FUNDEB (Brasil, 2007), as diferenças entre os Estados e municípios da confederação permanecem. O processo de municipalização tem se transformado em apenas transferências de encargos e de gastos do Estado central; no entanto as problemáticas têm se acentuado dado às condições diversas que são encontradas nas diferentes regiões e localizações. Apesar dos empréstimos que os países latinoamericanos têm se submetido, a educação não têm sido prioridade na maioria deles (Trojan, 2009), pois a média de investimentos na educação, neste período, não tem aumentado em relação ao Produto Interno Bruto (PIB) de cada nação, apesar do monitoramento da UNESCO. Além disso, as políticas internacionais de avaliação não conseguem identificar, conforme já afirmamos anteriormente, as problemáticas internas de cada país. Essa condição de avaliação exige estudos 
mais específicos de acordo com as condições de cada região, da esfera política e geográfica. Conforme observado ao longo do texto e de acordo com Oliveira (2005), nessas duas últimas décadas, os principais impactos educacionais no âmbito da América Latina deram-se por meio de políticas de regulação, ou seja, sistemas de avaliação em todas as modalidades educativas, especialmente no Brasil.

\section{Considerações finais}

Caracterizar as políticas públicas educacionais no contexto da América Latina em relação às duas últimas décadas foi uma tentativa bastante complexa, dada a sua heterogeneidade de condições e padrões culturais, étnicos, econômicos e sociais. No entanto, pode-se afirmar que todas as nações latino-americanas vêm sofrendo impacto de decisões tomadas por várias instituições internacionais sobre a política vigente. Nessas duas décadas (1990 e 2000), reformas e ajustes estruturais vêm sendo implementados os quais têm afetado os diversos setores de cada país, em especial o da educação. Nessa trama, o Estado vem se descomprometendo com compromissos já assumidos pela LDB de 1996, no caso brasileiro, ao envolver-se na tônica da ordem mundial, tentando engajar-se na tendência mundial do livre mercado ao assumir políticas públicas educacionais neoliberais dirigidas pelo pleito da economia global.

O que se percebe é uma continuidade histórica de dependência econômica, política e, também, educacional de países centrais do globo. As políticas públicas educacionais e as diretrizes que as fundamentam são elaboradas em um campo autoritário, por disputas e embates essencialmente econômicos e que vêm se efetivando apesar dos interesses antagônicos dos países considerados subalternos ou dependentes. Portanto, a síntese dessas políticas são resultados desses territórios de lutas contraditórios e que trazem subjacentes, em maior ou em menor intensidade, os desejos e os interesses de grupos, que certamente não são representantes da maioria dos destinatários.

Cabe a cada um de nós, pesquisadores, professores e cidadãos comuns avaliar a consistência dessas propostas que, em tese, deverão chegar às salas de aula, contexto no qual a aprendizagem efetivamente ocorre. E lá, conforme Libâneo (2006), é que podem ser avaliadas todas as fronteiras que a sociedade complexa e neoliberal impõe, especialmente no contexto das políticas educacionais da América Latina. Dessa forma, construir políticas públicas a partir das condições internas, considerando suas necessidades e suas peculiaridades, em um contexto democrático, pode ser uma utopia a ser vivida. Sabemos que, para isso, condicionantes econômicos, políticos e culturais impactam diretamente na consolidação de políticas educacionais democratizantes as quais levem em conta os anseios da maioria, das condições locais, e não apenas de grupos hegemônicos, e que possam ser legitimamente recriadas na prática das escolas.

Em uma análise cuidadosa, pode-se perceber, entretanto, que as políticas públicas educacionais de descentralização, a partir das quais se fomenta a criação de "fundos", a exemplo do FUNDEB, para propagar e disseminar o ideário neoliberal que gira em torno da gestão descentralizada, especialmente pelas propostas de municipalização do ensino, podem significar uma forma de minimização do Estado ainda maior. Em síntese, vale ressaltar, com maior criticidade, os aparentes progressos dos processos instalados no interior de um ideário político capitalista neoliberal. Não que aqui pretendemos extrapolar todas as questões em torno das políticas públicas educacionais no seio da América latina, mas acreditamos ter lançado algumas luzes para melhor refletir e compreender a trama dessa temática. 


\section{REFERÊNCIAS}

Adrião, Theresa et al. (2009). "Uma modalidade peculiar de privatização da educação pública: a aquisição de 'sistemas de ensino' por municípios paulistas". Educação e Sociedade, Campinas 30(108), pp. 799-818.

Alves, Fátima. (2007). "Qualidade da Educação fundamental: integrando desempenho e fluxo escolar". Ensaio: avaliação de políticas públicas Educacionais 15(57), pp. 525-542.

Arelaro, Lisete. (2008). “A não-transparência nas relações público-privadas: o caso das creches conveniadas”. In: Adrião, T.; Peroni, V. (orgs.). Público e Privado na Educação: novos elementos para o debate. São Paulo: Xamã, pp. 51-66.

Brasil. (1997). Presidência da República. Casa Civil. Subchefia para Assuntos Jurídicos. Decreto ${ }^{\circ}$ 2.264, de 27 de junho de 1997. Regulamenta a Lei no 9.424, de 24 de dezembro de 1996, no âmbito federal, e determina outras providências. Diário Oficial da União - Seção 1 28/6/1997, p. 13.660.

Brasil. (2007). Presidência da República. Casa Civil. Subchefia para Assuntos Jurídicos. Lei $n^{o}$ 11.494, de 20 de junho de 2007. Regulamenta o Fundo de Manutenção e Desenvolvimento da Educação Básica e de Valorização dos Profissionais da Educação - FUNDEB. Acessado junho 20,2014, http://www.planalto.gov.br/ccivil_03/_ato2007-2010/2007/lei/111494.htm.

Borón, Atílio. (2003). "A sociedade civil depois do dilúvio neoliberal”. In: Sader, E.; Gentili, P. (Orgs.) Pós-neoliberalismo: as políticas sociais e o estado democrático. 6. ed. São Paulo: Paz e Terra, pp. 63-118.

Cury, Carlos Roberto J. (2001). "Políticas públicas: diretrizes e necessidades da educação básica". In: Encontro de Educação do Oeste Paulista, 3., Marília. Anais. Marília: UNESP, pp. 1-3.

Damásio, Maria Lúcia Francisco. (2008). "Impactos das diretrizes internacionais nas políticas públicas educacionais brasileiras”. Revista Novas Idéias 1(1), pp. 07-24.

Dourado, Luiz F. (2007). "Políticas e gestão da educação básica no Brasil: limites e perspectivas". Educação \& Sociedade 28(100), pp. 921-946.

Libâneo, José Carlos. (2006). "Sistema de ensino, escola, sala de aula: onde se produz a qualidade das aprendizagens?" In: Lopes, Alice C.; Macedo, Elizabeth (orgs.). Politicas de currículo em múltiplos contextos. São Paulo: Cortez, pp. 70-126.

Luz, Gizeli; e Gesser, Verônica. (2007). "FUNDEF: Reflexões sobre sua contribuição no desenvolvimento profissional de professores". In: Villela, Elisabeth C.; Raitz, Tânia R. (orgs.). Educação e Trabalho. Itajaí: Univali, pp. 71-81.

Oliveira, Dalila Andrade. (2005). "Regulação das políticas educacionais na América latina e suas conseqüências para os trabalhadores docentes". Educação \& Sociedade 26(92), pp. 753-775.

Santos, Boaventura de Sousa (2012). Parceria público-privadas e justiça. Uma análise comparada de diferentes experiências. Relatório do observatório permanente da justiça portuguesa. Centro de Estudos Sociais. Universidade de Coimbra. 2007. Acessado dezembro 6, 2012, http://opj.ces.uc.pt/pdf/rel_parcerias_publico_privadas_justica.pdf.

Santos, Vivian Matias dos. (2008). "Políticas Públicas em Educação: a "lógica subalternizante" vigente na América Latina e seus reflexos na universidade brasileira". Emancipação 8(1), pp. 79-93.

Souza, a. L. L. De (2002). "Estado e educação pública: tendências administrativas e de gestão". In: Oliveira, D. A.; Rosar, M.F.F. (orgs.). Política e Gestão da Educação. Autêntica, Belo Horizonte, pp. 89-103.

Sposati, Aldaíza. (2011). "Tendências latino-americanas da política social pública no século 21". Revista Katál 14(1), pp. 104-115.

Trojan, Rose Meri. (2009). "Políticas Educacionais na América Latina: tendências em curso". Revista Ibero-americana de Educação, 51(1), pp. 1-12.

Unesco. (1990). Declaração mundial sobre Educação para todos e plano para satisfazer às necessidades básicas de aprendizagem. Aprovada pela conferência Mundial sobre 
Educação para todos e Satisfação das Necessidades Básicas de aprendizagem, Jontiem, Tailândia.

\section{SOBRE AS AUTORAS}

Verônica Gesser: Doutora em Educação pela Florida International University. Professora e Pesquisadora do PPGE da Universidade do Vale do Itajaí, Univali, SC. Líder do grupo de pesquisa Políticas Públicas de Currículo e Avaliação credenciado no CNPQ.

Valéria Silva Ferreira: Doutora em Psicologia da Educação pela Pontifícia Universidade Católica de São Paulo. Professora e Pesquisadora do PPGE da Univali, SC. Líder do grupo de pesquisa Contextos educativos e Práticas Docentes, credenciado no CNPQ. 